\title{
Awareness on Different Dental Implant Components Among General Dental Practitioners
}

\author{
Akshaya. $\mathrm{K}^{1}$ and Suresh Venugopalan ${ }^{2}$ \\ ${ }^{1}$ Saveetha Dental college \& Hospitals, Saveetha Institute of Medical \\ and Technical Science, Saveetha University, Chennai \\ ${ }^{2}$ Reader Department of Prosthodontics, Saveetha Dental college \& Hospitals, Saveetha \\ Institute of Medical and technical Science, Saveetha University, Chennai, India
}

\section{ABSTRACT}

The use of dental implants for the replacement of missing teeth has been increased by leaps and bounds ever since the concept of osseointegration has been identified and undertaken. Recent publicity about the advantages of implant dentistry has generated considerable interest among dental professionals and the general public population. A dental implant kit has various surgical and prosthetic components that aids the practitioner during each phase of implant selection to placement. Thus the aim of the current study is to assess the awareness of different surgical and prosthetic components available in a dental implant kit and also to assess knowledge on recent updates on dental implants among general dental practitioners. The present study was a cross sectional questionnaire study that was carried out to assess the knowledge on different dental implant components among general dental practitioners. A total of 120 subjects participated in the study. The study involved completion of a predesigned questionnaire that had questions on precision osteotomy drills, dense bone drills, impression coping, straight and engaging abutments. The responses were tabulated in excel and were subjected to statistical analysis in SPSS by IBM. From the statistical analysis it is clear that almost 70\% of the respondents are aware of different dental components and techniques, yet only two third of them use it during their regular practice. For example, With regard to use of precision osteotomy drills, almost 85\% of practitioners think they are useful yet only $69.1 \%$ of dental practitioners use them during the course of treatment. The overall awareness on different dental implant components among dentists were appreciable. Further CDE programmes can be conducted to bring awareness on key dental implant surgical or prosthetic components among dental practitioners.

KEY WORDS: DENTAL IMPLANTS, PRECISION OSTEOTOMY, PARALLELING PINS, ENGAGING ABUTMENTS, IMPRESSION COPING.

\section{INTRODUCTION}

Implant dentistry has evolved into the mainstream of restorative practices everywhere in the world.(Misch,

\section{ARTICLE INFORMATION}

*Corresponding Author: suresh@saveetha.com

Received 13th June 2020 Accepted after revision 7th August 2020

Print ISSN: 0974-6455 Online ISSN: 2321-4007 CODEN: BBRCBA

Thomson Reuters ISI Web of Science Clarivate Analytics USA and Crossref Indexed Journal

\section{Clarivate
Analytics}

NAAS Journal Score 2020 (4.31) SJIF: 2020 (7.728)

A Society of Science and Nature Publication,

Bhopal India 2020. All rights reserved.

Online Contents Available at: http//www.bbrc.in/

Doi: http://dx.doi.org/10.21786/bbrc/13.7/90
2001) The two significant phases are a surgical phase and a prosthodontic phase. For hundreds of years, there have been ways to exchange the crown but not the root but root replacement is now possible. Endosseous dental implants are alternative tooth roots and implant-supported prostheses are considered the simplest substitute for missing teeth.(Hatim, Al-Rawee and Tawfeeq, 2006) The use of dental implants for restorations has revolutionized patient care and has given solutions for those clinical conditions, wherein conventional prosthodontics has not given satisfactory outcomes.(Lindh et al., 1998).

Within the early years of implantology, dental implants were targeted at replacing the completely edentulous

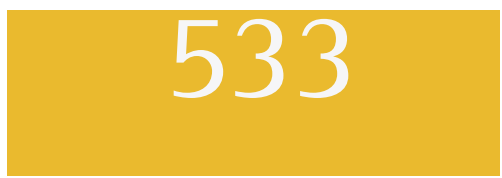


foundations. However, with the increased awareness of dental implants concerning its function and esthetics, more and more patients are choosing implant treatment even for the replacement of one missing tooth.(Lee et al., 2005) A typical dental implant includes the implant body which is a part of the implant designed to be surgically placed into the bone. Root form implants are the common implant body form, with a screw design aimed to strongly fix the implant to the bone. The abutment is the part of the implant that serves to support and/or retain the suprastructure.(Misch, 1999)

Implantology has shifted from a "surgically driven approach" to a "prosthetically driven approach", because pertinent implant positioning is important in achieving long-term esthetic and functional success. (Abou-Rabii, 2017) In the meantime computer-guided implant surgery has been developed for over 20 years. This digital technology is now commonly recommended because it can reduce inaccuracy in terms of implant positioning.(Vercruyssen et al., 2015) Today, two forms of guided implant surgery systems are developed: static and dynamic navigation. The static approach (static guided implant surgery) refers to the utilization of a surgical guide (drilling template) in implant surgery. The surgical guide can confine the direction and depth of the implant bed preparation and implant placement so a virtually planned implant position may be transferred to the implant site.(Pyo et al., 2019) Currently, the static system is more popular, because dynamic navigation needs additional expense and space for the equipment. (Lin et al., 2020)

The first step in ensuring the passive fit of an implant is to create an accurate impression and to transfer the 3-dimensional positions of implants into the laboratory models.(Wee, 2000) Due to the aesthetic and anatomical limitations, it is not always possible to position the implants parallel to each other. It has been stated that in the event of having 4 to 6 implants, the impressions made up of parallel implants show higher accuracy than those made from angulated implants.(Sorrentino et al., 2010; Akalin, Ozkan and Ekerim, 2013; Ozan and Hamis, 2019) In the case where multiple implants are available and an angular difference of quite $15^{\circ}$ exists between implants or impression copings, the utilization of open-tray (direct) impression technique and splinting of impression copings are recommended.(Lee et al., 2008) (Kurtulmus-Yilmaz et al., 2014).

The foremost preferred impression materials in implant dentistry are polyether and vinyl poly-siloxane.(Baig, 2014) The impression material utilized in the opentray impression technique must show sufficient rigidity to maintain the position of the impression coping and forestall it from being displaced during removal. Splinting the impression copings is suggested so as to increase the accuracy of impression and avoid the distortion of impression material, particularly while fastening the implant analogs to their respective copings.(Mojon et al., 1990; Vigolo, Majzoub and Cordioli, 2003)
There are thus, a variety of techniques and technologies improved recently to aid through the surgical flow of implant placement. Also there are various surgical and prosthetic components in an implant dental kit that aids in the above mentioned process. A thorough knowledge on all the dental implant components available is necessary to avoid implant failures and further intra and post operative complications and to achieve better patients compliance. Previously our department has published extensive research on various aspects of prosthetic dentistry ('Evaluation of Corrosive Behavior of Four Nickel-chromium Alloys in Artificial Saliva by Cyclic Polarization Test:An in vitro Study', 2017; Ganapathy, Kannan and Venugopalan, 2017; Jain, 2017a, 2017b; Ranganathan, Ganapathy and Jain, 2017; Ariga et al., 2018; Gupta, Ariga and Deogade, 2018; Anbu et al., 2019; Ashok and Ganapathy, 2019; Duraisamy et al., 2019; Varghese, Ramesh and Veeraiyan, 2019), this vast research experience has inspired us to research about the knowledge that general dental practitioners have on various dental implant components. Thus, the objective of the current study is to assess the knowledge, attitude and practice on different surgical and prosthetic dental implant components among general dental practitioners.

\section{MATERIAL AND METHODS}

The present study was a cross sectional questionnaire study that was carried out to assess the knowledge on different dental implant components among general dental practitioners. A total of 120 subjects participated in the study. The survey period extended for a period of 20 days in April 2019. The study involved completion of a predesigned questionnaire that had questions on precision osteotomy drills, multiple implants, paralleling pins, dense bone drills, cover screw, impression coping, engaging, non-engaging, straight and universal abutments.

\section{Eligibility criteria}

Inclusion criteria: General dental practitioners who had had an experience of placing dental implants were included for the study.

Exclusion criteria: Dental practitioners with no experience of placing implants previously were excluded from the study.

Structure of the questionnaire: The study involved completion of a predesigned questionnaire containing 2 sections. Section I includes, demographic characteristics like name, age, gender and year of experience of the participants. Section two had questions on precision osteotomy drills, multiple implants, paralleling pins, dense bone drills, cover screw, impression coping, engaging, non-engaging, straight and universal abutments. A total of 15 questionnaires, which had been designed based on the primary objective of the study, were used. The questionnaire was prepared in English. The participants were asked to put the responses in a questionnaire. The 
Data was Shortlisted, recorded in excel and was subjected to statistical analysis in SPSS by IBM.

\section{RESULTS AND DISCUSSIONS}

From the statistical analysis done in SPSS by IBM, it can be observed that most of the respondents have responded positively to the questions provided. Most of the dental practitioners have had a sound knowledge on various dental implant components yet, many of those aren't currently using them during general practice. With regard to use of precision osteotomy drills, almost $85 \%$ of practitioners think they are useful yet only $69.1 \%$ of dental practitioners use them during the course of treatment $(G r a p h 1,2)$. Of those who use precision osteotomy drills only $39.1 \%$ of them use it for re-positioning (Graph 3). Of those who are aware of Precision osteotomy drills and its uses, $77.5 \%$ of general dental practitioners think that precision osteotomy drills are helpful in achieving a good point of entry, also 68.3\% of practitioners felt that precision osteotomy drills had served while planning multiple implants (Graph 4, 5).

Graph 1: Pie chart showing the response of dental practitioners for the question 'Have you used precision osteotomy drills?'. Yes is represented in blue and no in green. It is evident from the graph that $69.1 \%$ of general dental practitioners had used precision osteotomy drills during implant placement procedures.

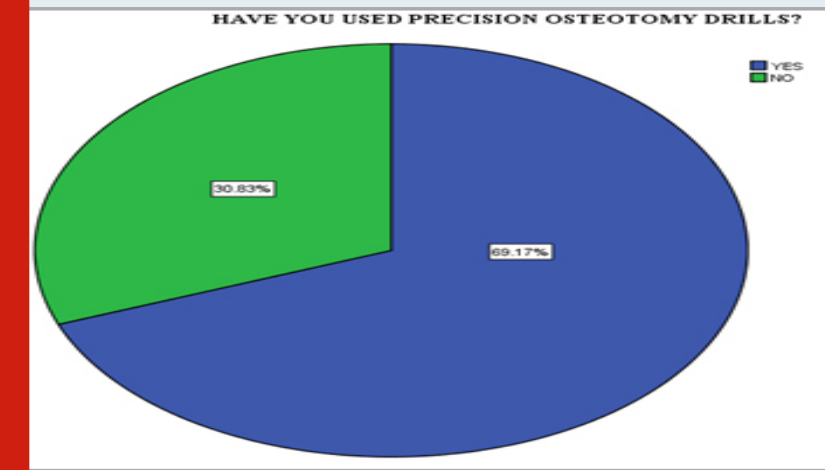

Graph 2: Pie chart showing the response of dental practitioners for the question 'Do you think precision osteotomy drills are helpful?'. Yes is represented in blue no in green and may be in red. It is evident from the graph that $85 \%$ of general dental practitioners feel precision osteotomy drills are helpful.

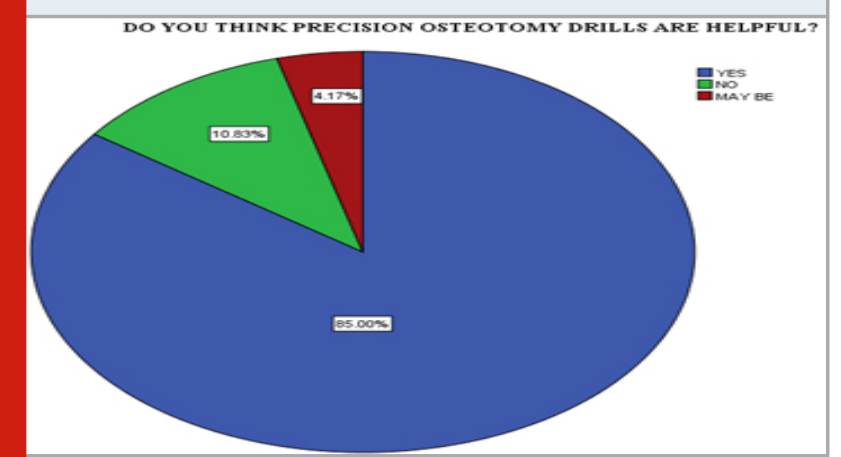

Graph 3: Pie chart showing the response of dental practitioners for the question 'Have you used precision osteotomy drills for repositioning?':Yes is represented in blue, no in green and rarely in red. It is evident from the graph that 39\% of general dental practitioners feel precision osteotomy drills are helpful during repositioning.

HAVE YOU USED PRECISION OSTEOTOMY DRILLS FOR RE-POSITIONING?

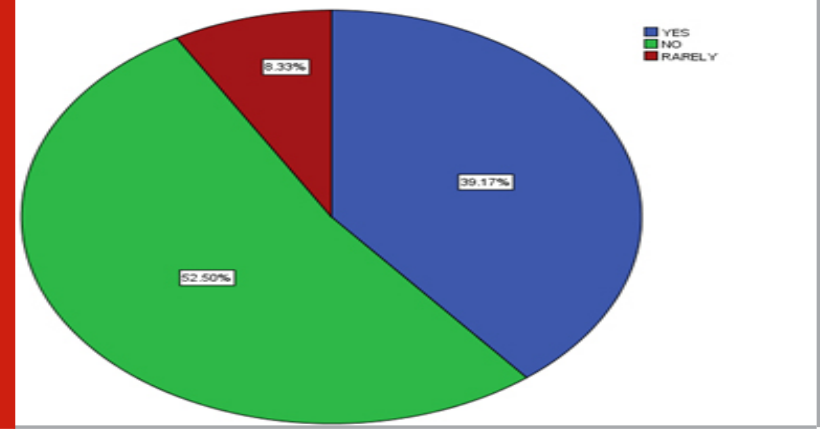

Graph 4: Pie chart showing the response of dental practitioners for the question 'Do you find precision osteotomy drills being helpful in achieving a good point of entry?'YYes is represented in blue, no in green and not aware of in red. It is evident from the graph that $77.5 \%$ of general dental practitioners feel precision osteotomy drills are helpful in achieving a good point of entry

DO YOU FIND PRECISION OSTEOTOMY DRILLS BEING HELPFUL IN ACHIEVING

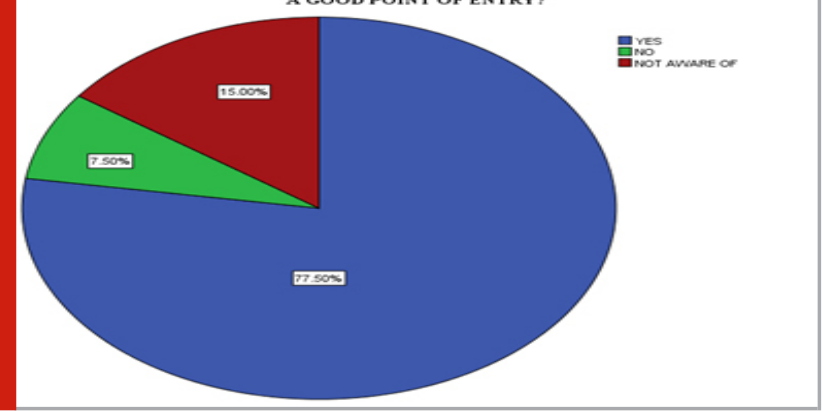

Graph 5 : Pie chart showing the response of dental practitioners for the question 'At the time of planning multiple implants had precision osteotomy drills served in any way?'Yes is represented in blue, no in green and not aware of in red. It is evident from the graph that $68.3 \%$ of general dental practitioners feel precision osteotomy drills are helpful while planning multiple implants.

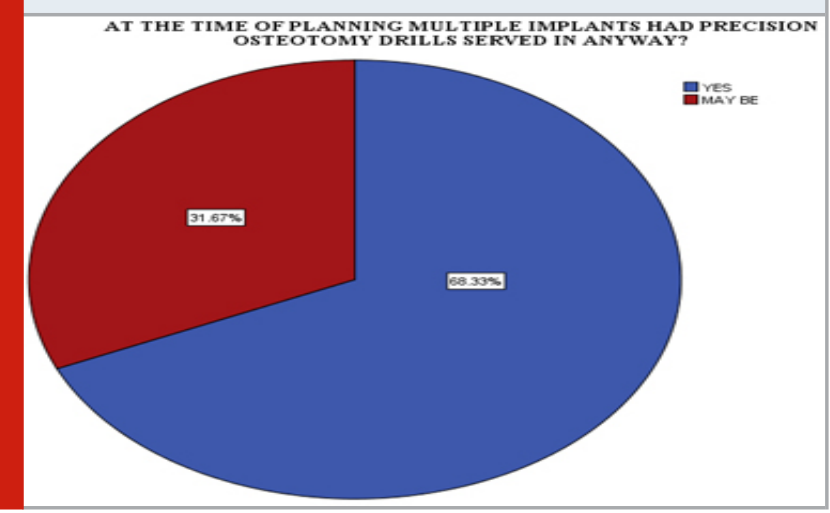


With regard to questions on paralleling pins, 54.1\% of practitioners use paralleling pins in almost all the cases and $75.5 \%$ of them use paralleling pins to check parallelism between two osteotomy sites while, $41.6 \%$ of practitioners use paralleling pins during every stage of osteotomy to check osteotomy length (Graph 6, 7, 8). Also, 55\% of practitioners use dense bone drills during surgical implantology (Graph 9). Of the total respondents, 91.6\% of practitioners use cover screw or healing abutments immediately during stage 1 surgery (Graph 10). During stage 2 of implant procedure $84 \%$ of practitioners use impression copings (Graph 11). Of those who use impression copings, 75\% of practitioners use open tray impression copings for full mouth rehabilitation cases (Graph 12). When questioned about abutment selections, $88.3 \%$ of the practitioners use straight abutments (Graph 13). Also in multiple implant cases $67.2 \%$ of practitioners had preferred engaging abutments over non-engaging abutments (Graph 14). With regard to universal abutments $83.3 \%$ of practitioners were aware of those (Graph 15).

Graph 6: Pie chart showing the response of dental practitioners when questioned about use of paralleling pins in every cases.Yes is represented in blue, no in green and rarely used in red. It is evident from the graph that $54.1 \%$ of general dental practitioners use paralleling pins in almost all cases.

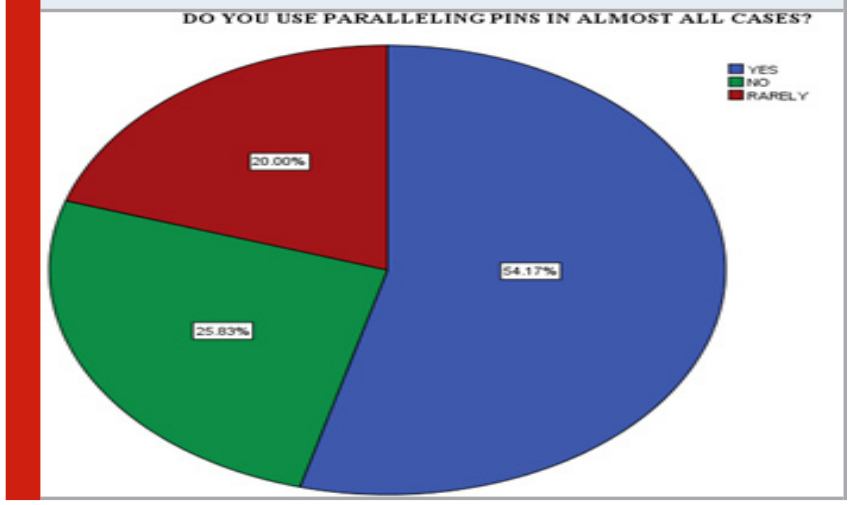

Graph 7: Pie chart showing the response of dental practitioners when questioned on checking parallelism between two implants. Yes is represented in blue, no in green and rarely used in red. It is evident from the graph that $77.5 \%$ of general dental practitioners use paralleling pins to check parallelism between two implants.

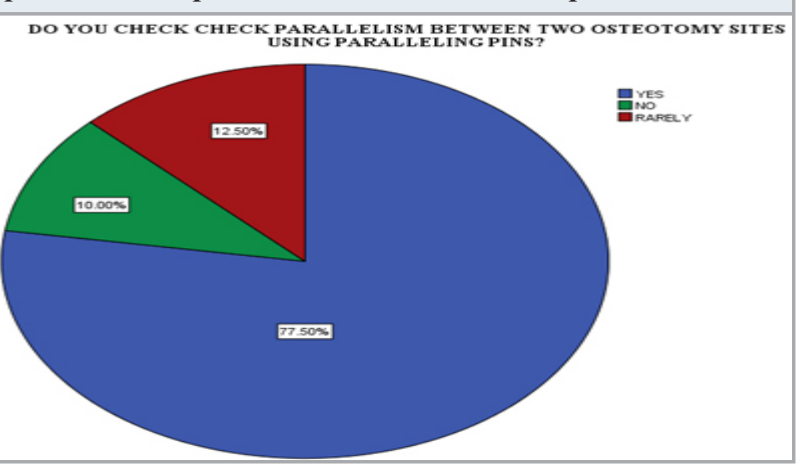

Graph 8: Pie chart showing the response of dental practitioners when questioned on usage of paralleling pins to check osteotomy length. Yes is represented in blue, no in green and rarely used in red. It is evident from the graph that $41.6 \%$ of general dental practitioners use paralleling pins to check osteotomy length.

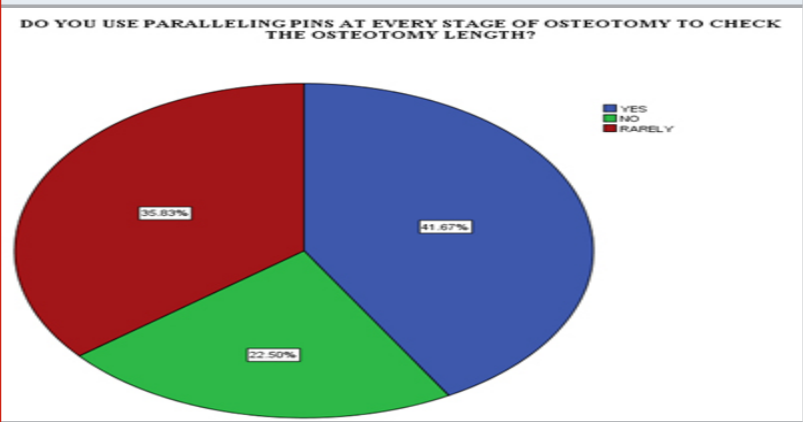

Graph 9: Pie chart showing the response of dental practitioners when questioned on usage of dense bone drills. Yes is represented in blue and no in green. It is evident from the graph that 55\% of general dental practitioners use dense bone drills during surgical implantology.

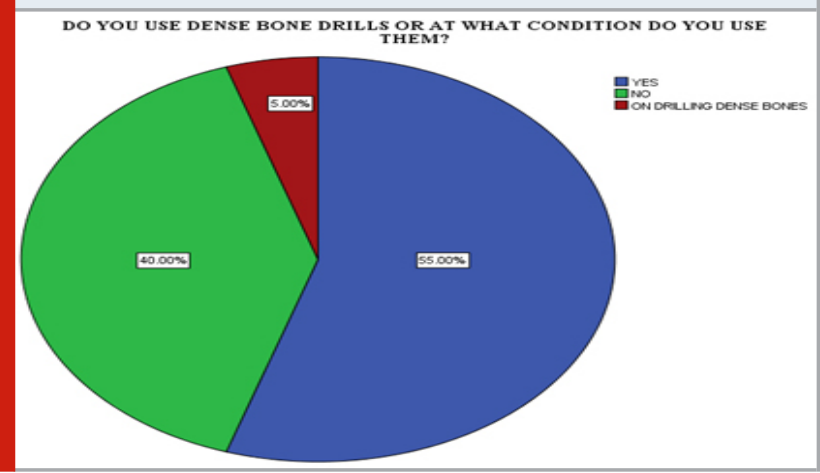

Graph 10: Pie chart showing the response of dental practitioners when questioned on usage of cover screw and healing abutments. Yes is represented in blue and no in green. It is evident from the graph that $91.6 \%$ of general dental practitioners use dense cover screw or healing abutments immediately at stage 1 surgery.

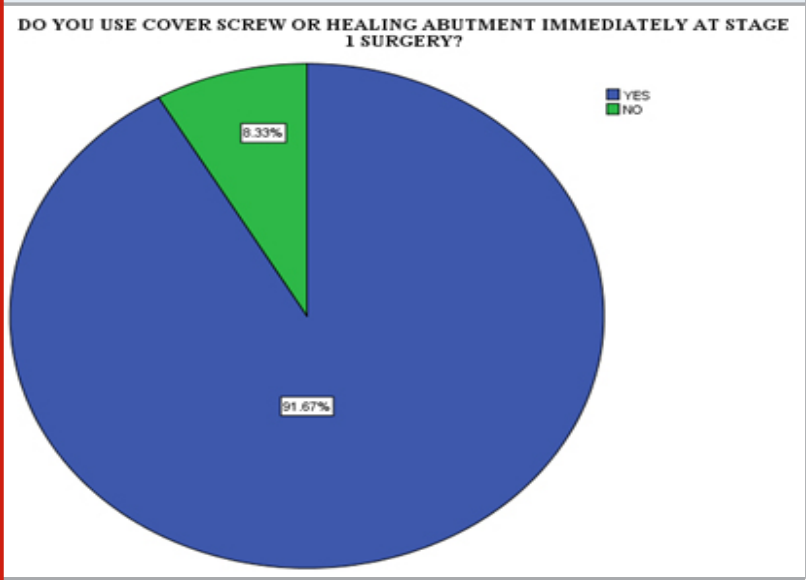


Graph 11: Pie chart showing the response of dental practitioners when questioned on usage of impression copings. Yes is represented in blue and no in green It is evident from the graph that $84.1 \%$ of general dental practitioners use impression copings at stage 2 implant procedures.

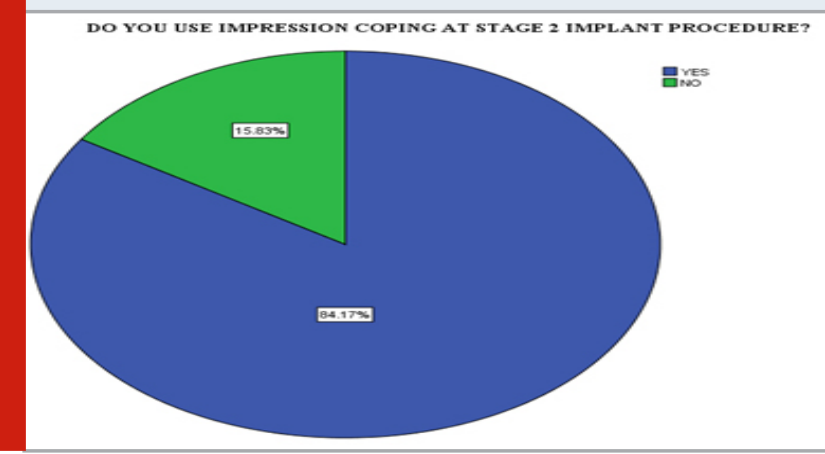

Graph 12: Pie chart showing the response of dental practitioners when questioned on usage of open tray impression copings for full mouth rehabilitation. Yes is represented in blue and no in green It is evident from the graph that $75 \%$ of general dental practitioners use open tray impression copings for full mouth rehabilitation.

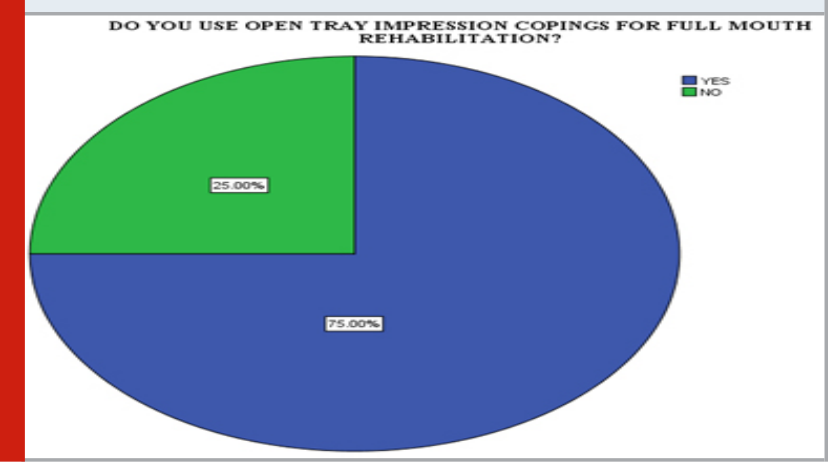

Graph 13: Pie chart showing the response of dental practitioners when questioned on usage of straight abutments. Yes is represented in blue, no in green, both straight and angulated abutments in grey and screw retained abutments in red. It is evident from the graph that $88.3 \%$ of general dental practitioners use straight abutments.

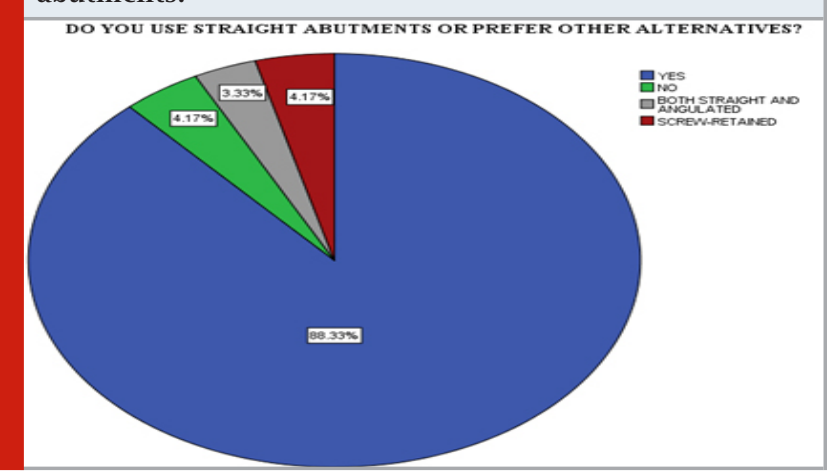

Graph 14: Pie chart showing the response of dental practitioners when questioned on abutment selection during multiple implant cases. Engaging abutments are represented in blue and non engaging in green. It is evident from the graph that $67.2 \%$ of general dental practitioners prefer engaging abutments while planning multiple implant cases.

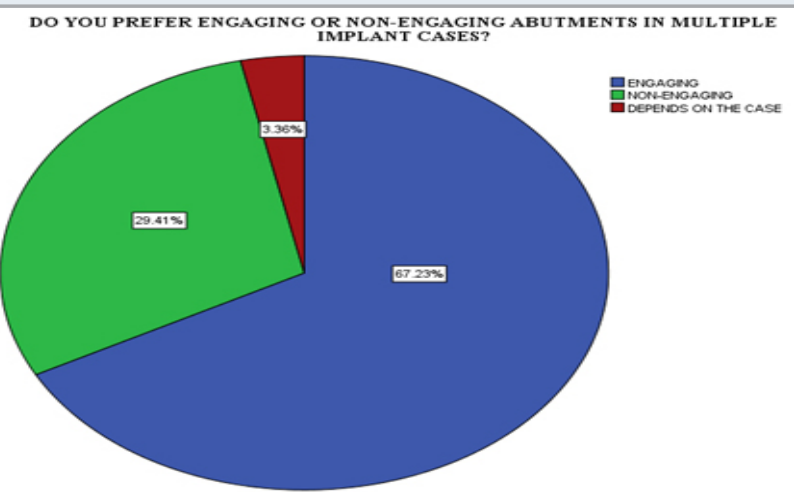

Graph 15: Pie chart showing the response of dental practitioners when questioned on universal abutments. Yes is represented in blue and no in green. It is evident from the graph that $83.3 \%$ of general dental practitioners are aware of universal abutments.

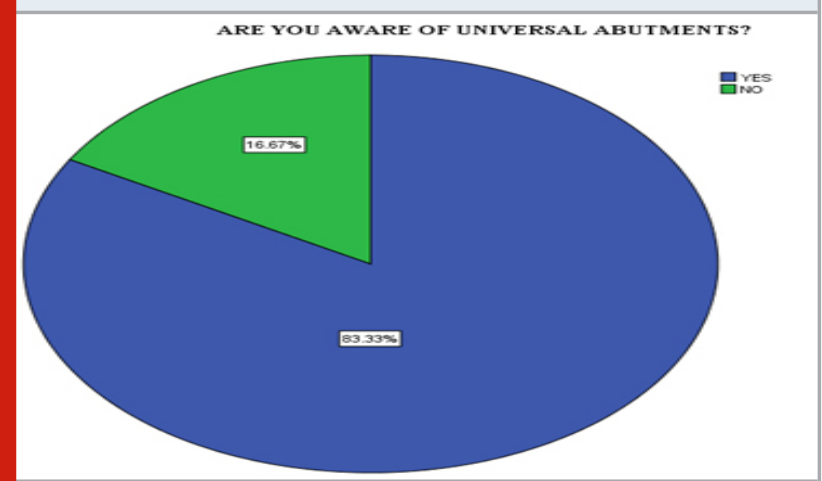

Dental implants have a high success rate for managing edentulous space despite complex cases such as maxillary sinus lift and lateral ridge augmentation.(Del Fabbro et al., 2004) With regard to the protocol followed during implant placements, firstly precision rills are used to create a purchase point and to penetrate the cortical bone, followed by this pilot drills are used that basically helps in establishing the length and direction of the implant placement. The third step is the use of a position indicator which is used to check the placement and angulation of implants. Once that is checked, intra oral periapical radiographs of the specific region is taken to stay aware of the adjacent anatomical landmarks. Succeeding this, sequential drilling is done, followed by the placement of adaptors. Finally primary stability values are checked and a waiting period of about 6 months is recommended.

Precision osteotomy drills facilitate initial soft tissue penetration and creation of an initial crestal starting point (also for flap procedure), with contrast marking 
to prepare the site to the correct depth and thus aids durig implant procedures. In the current study, 85\% of practitioners think precision osteotomy drills are useful of which only $77.5 \%$ of general dental practitioners think that precision osteotomy drills are helpful in achieving a good point of entry, also $68.3 \%$ of practitioners felt that precision osteotomy drills had served while planning multiple implants, yet only $69.1 \%$ of dental practitioners use them constantly during the course of treatment. Of those who use precision osteotomy drills only $39.1 \%$ of them use it for re-positioning. Also, only $52 \%$ of practitioners use prallying pins in almost all cases, two third of the respondents use them only to check parallelism and only half of them use it to check the osteotomy length. From the above statistics it can be analysed that though a appreciable percentage of dental practitioners are aware of the uses of precision osteotomy drills and paralleling pins only two-third of them tend to use those during treatment procedures. This result is similar to the one conducted by Narendra et al, in 2013 who stated that many dental doctors had basic knowledge of dental implants yet were not actively practicing dental implants.(Basutkar, 2013)

Table 1. Showing the responses in percentage made by general dental practitioners for each option given for every question in the questioner.

\begin{tabular}{|c|c|c|c|}
\hline Sn no. & Questions & options & Responses in percentage \\
\hline 1. & $\begin{array}{l}\text { Have you used precision } \\
\text { osteotomy drills? }\end{array}$ & $\begin{array}{l}\text { 1. Yes } \\
\text { 2. No }\end{array}$ & $\begin{array}{l}\text { 1. } 69.1 \% \\
\text { 2. } 30.8 \%\end{array}$ \\
\hline 2. & $\begin{array}{l}\text { Do you think precision } \\
\text { osteotomy drills are helpful? }\end{array}$ & $\begin{array}{l}\text { 1. Yes } \\
\text { 2. No } \\
\text { 3. May be }\end{array}$ & $\begin{array}{l}1.85 \% \\
\text { 2. } 10.8 \% \\
\text { 3. } 4.1 \%\end{array}$ \\
\hline 3. & $\begin{array}{l}\text { Have you used precision } \\
\text { osteotomy drills for repositioning? }\end{array}$ & $\begin{array}{l}\text { 1.Yes } \\
\text { 2. No } \\
\text { 3. Rarely }\end{array}$ & $\begin{array}{l}\text { 1. } 52.5 \% \\
\text { 2. } 39.1 \\
\text { 3. } 8.3 \%\end{array}$ \\
\hline 4. & $\begin{array}{l}\text { Do you find precision osteotomy } \\
\text { drills being helpful in }\end{array}$ & $\begin{array}{l}\text { 1. Yes } \\
\text { 2. No }\end{array}$ & $\begin{array}{l}\text { 1. } 77.5 \% \\
\text { 2. } 15 \%\end{array}$ \\
\hline 5. & $\begin{array}{l}\text { achieving a good point of entry? } \\
\text { At the time of planning } \\
\text { multiple implants had } \\
\text { precision osteotomy drills } \\
\text { served in anyway? }\end{array}$ & $\begin{array}{l}\text { 3. Not aware } \\
\text { 1. Yes } \\
\text { 2. No } \\
\text { 3. May be }\end{array}$ & $\begin{array}{l}\text { 3. } 7.5 \% \\
\text { 1. } 68.3 \% \\
\text { 2. } 0 \\
\text { 3. } 31.6 \%\end{array}$ \\
\hline 6. & $\begin{array}{l}\text { Do you use paralleling } \\
\text { pins in almost all cases? }\end{array}$ & $\begin{array}{l}\text { 1. Yes } \\
\text { 2. No } \\
\text { 3. Rarely }\end{array}$ & $\begin{array}{l}\text { 1. } 54.1 \% \\
\text { 2. } 25.8 \% \\
\text { 3. } 20 \%\end{array}$ \\
\hline 7. & $\begin{array}{l}\text { Do you check parallelism } \\
\text { between two osteotomy } \\
\text { sites using paralleling pins? }\end{array}$ & $\begin{array}{l}\text { 1. Yes } \\
\text { 2. No } \\
\text { 3. Rarely }\end{array}$ & $\begin{array}{l}\text { 1. } 77.5 \% \\
\text { 2. } 10 \% \\
\text { 3. } 12.5 \%\end{array}$ \\
\hline 8. & $\begin{array}{l}\text { Do you use paralleling } \\
\text { pins at every stage of } \\
\text { osteotomy to check } \\
\text { the osteotomy length? }\end{array}$ & $\begin{array}{l}\text { 1. Yes } \\
\text { 2. No } \\
\text { 3. Rarely }\end{array}$ & $\begin{array}{l}\text { 1. } 41.6 \% \\
\text { 2. } 22.5 \% \\
\text { 3. } 35.8 \%\end{array}$ \\
\hline 9. & $\begin{array}{c}\text { Do you use dense bone } \\
\text { drills or at what } \\
\text { condition do you use them? }\end{array}$ & $\begin{array}{l}\text { 1. Yes } \\
\text { 2. No } \\
\text { 3. On drilling } \\
\text { dense bones }\end{array}$ & $\begin{array}{l}11.55 \% \\
2.40 \% \\
\text { 3. } 5 \%\end{array}$ \\
\hline 10. & $\begin{array}{c}\text { Do you use cover screw } \\
\text { or healing abutments } \\
\text { immediately at stage } 1 \text { surgery? }\end{array}$ & $\begin{array}{l}\text { 1.Yes } \\
\text { 2.No }\end{array}$ & $\begin{array}{l}1.91 .6 \% \\
2.8 .3 \%\end{array}$ \\
\hline 11. & $\begin{array}{l}\text { Do you use impression } \\
\text { coping at stage } 2 \text { implant procedure? }\end{array}$ & $\begin{array}{l}\text { 1. Yes } \\
\text { 2.No }\end{array}$ & $\begin{array}{l}\text { 1. } 84.1 \% \\
\text { 2. } 15.8 \%\end{array}$ \\
\hline 12. & $\begin{array}{l}\text { Do you use impression } \\
\text { copings for full mouth rehabilitation? }\end{array}$ & $\begin{array}{l}\text { 1. Yes } \\
\text { 2. No }\end{array}$ & $\begin{array}{l}\text { 1. } 75 \% \\
\text { 2. } 25 \%\end{array}$ \\
\hline 13. & $\begin{array}{l}\text { Do you use straight abutments } \\
\text { or prefer other alternatives? }\end{array}$ & \begin{tabular}{|c} 
1. Yes \\
2. No \\
3.Both straight
\end{tabular} & $\begin{array}{l}1.83 .3 \% \\
2.4 .1 \% \\
\text { 3. } 3.3 \%\end{array}$ \\
\hline
\end{tabular}




\begin{tabular}{|c|c|c|c|}
\hline \multirow{4}{*}{14.} & & \\
\multirow{2}{*}{14.} & and angulated & & \\
& 4. Screw retained & 4. $4.1 \%$ & \\
& Dp you prefer engaging or non- & 1.Engaging & $1.67 .2 \%$ \\
& engaging abutments & 2. Non-engaging & 2. $29.4 \%$ \\
\hline 15. & in multiple implant cases? & 3. Depends on the case & $3.3 .3 \%$ \\
\hline & Are you aware of & 1.Yes & $1.83 .3 \%$ \\
& universal abutments? & 2.No & $2.16 .7 \%$ \\
\hline
\end{tabular}

There are several designs of standard abutments available today. They are fabricated out of titanium or zirconium alloys. An abutment may be selected with a fixed collar height $360^{\circ}$ for posteriors or a variable collar height called an esthetic abutment, for both anteriors and bicuspids.(Sen, Nazmiye and Us, 2019) With regard to abutment selections $88.3 \%$ of practitioners use straight abutments for their implant cases, $4.2 \%$ of them use screw-retained abutments while only 3.3\% of them use both straight and angulated abutments. This proves that, preference of abutments are certainly not the same with every doctor practicing dentistry. There are several choices in the decision tree that are available to the clinician regarding implant restorations. A custom or prefabricated abutment, straight or angulated, titanium or zirconium, able to be prepared or not, regular or esthetic collar, screw-type or cementable, can be used. (Sen, Nazmiye and Us, 2019)

When, restoratively, a custom abutment is required, a choice must be made between employing a closed or open tray transfer impression coping. The open tray in the hands of the novice clinician is simpler to achieve quick competency. The open tray impression coping is one that's screwed to the implant body and, to determine proper seating, it is radiographically verified. A hole is drilled through the stock plastic impression tray to permit the long screw to pass through the tray. Following which an impression is taken employing a rigid material. (Sen, Nazmiye and Us, 2019) Similarly, in the current study $75 \%$ of practitioners prefer open tray impression copings. Thus, it can be concluded that the overall knowledge on dental implants among dental practitioners can be still improved to avoid failures and complications during surgery.

With the current study as a platform, awareness on dental implant components among dental practitioners can be analysed and this will also enable dentists to gain a thorough knowledge on pros of different surgical and prosthetic components avail label. Limitations of this study include Geographic limitation as predominantly South Indian population of dentists were only considered, and was a Unicentric study with few Incomplete and unclear data. The Future scope of this study will yield a better and more accurate result when different ethnic populations are considered.

\section{CONCLUSIONS}

Within the limitations of the current study, it can be concluded that the majority of dentists are aware of different dental implant surgical or prosthetic components. The present study indicates use of paralleling pins to assess the positioning and length of the osteotomy site was lacking (57\%) and was lacking information on engaging and non engaging abutments (67\%). Since the protocol for implant surgery or components differs with different implant systems dentists tends to get misguided. Further CDE programmes can be conducted to raise awareness among dentists regarding the different dental implant components and key surgical components used -paralleling pins, precision osteotomy drills, abutment selection criteria to enable dental practitioners to master implant surgery.

\section{ACKNOWLEDGEMENTS}

The authors would like to acknowledge the help and support rendered by the department of Prosthodontics of Saveetha Dental College and Hospitals, SIMATS.

\section{Conflict of Interest:}

Nil.

\section{REFERENCES}

Abou-Rabii, I. (2017) 'Computer guided implant surgery, facts and myths', Dental Health: Current Research. doi: 10.4172/2470-0886-c1-001.

Akalin, Z. F., Ozkan, Y. K. and Ekerim, A. (2013) 'Effects of Implant Angulation, Impression Material, and Variation in Arch Curvature Width on Implant Transfer Model Accuracy', The International Journal of Oral \& Maxillofacial Implants, pp. 149-157. doi: 10.11607/ jomi.2070.

Anbu, R. T. et al. (2019) 'Comparison of the Efficacy of Three Different Bone Regeneration Materials: An Animal Study', European journal of dentistry, 13(1), pp. 22-28.

Ariga, P. et al. (2018) 'Determination of Correlation of Width of Maxillary Anterior Teeth using Extraoral and Intraoral Factors in Indian Population: A Systematic Review', World Journal of Dentistry, 9(1), pp. 68-75.

Ashok, V. and Ganapathy, D. (2019) 'A geometrical method to classify face forms', Journal of oral biology and craniofacial research, 9(3), pp. 232-235.

Baig, M. (2014) 'Accuracy of Impressions of Multiple Implants in the Edentulous Arch: A Systematic Review', The International Journal of Oral \& Maxillofacial Implants, pp. 869-880. doi: 10.11607/jomi.3233.

Basutkar, N. (2013) 'Assessment of knowledge related to implant dentistry in dental practitioners of north 
Karnataka region, India', Journal of Dental Implants, p. 26. doi: 10.4103/0974-6781.111681.

Del Fabbro, M. et al. (2004) 'Systematic review of survival rates for implants placed in the grafted maxillary sinus', The International journal of periodontics \& restorative dentistry, 24(6), pp. 565-577.

Duraisamy, R. et al. (2019) 'Compatibility of Nonoriginal Abutments With Implants: Evaluation of Microgap at the Implant-Abutment Interface, With Original and Nonoriginal Abutments', Implant dentistry, 28(3), pp. 289-295.

Evaluation of Corrosive Behavior of Four Nickelchromium Alloys in Artificial Saliva by Cyclic Polarization Test:An in vitro Study' (2017) World Journal of Dentistry, 8(6), pp. 477-482.

Ganapathy, D. M., Kannan, A. and Venugopalan, S. (2017) 'Effect of Coated Surfaces influencing Screw Loosening in Implants: A Systematic Review and Meta-analysis', World Journal of Dentistry, 8(6), pp. 496-502.

Gupta, P., Ariga, P. and Deogade, S. C. (2018) 'Effect of Monopoly-coating Agent on the Surface Roughness of a Tissue Conditioner Subjected to Cleansing and Disinfection: A Contact Profilometric Study', Contemporary clinical dentistry, 9(Suppl 1), pp. S122S126.

Hatim, N., Al-Rawee, R. and Tawfeeq, B. (2006) 'Criteria for selection of Implant cases', Al-Rafidain Dental Journal, pp. 161-170. doi: 10.33899/rden.2006.40136. Jain, A. R. (2017a) 'Clinical and Functional Outcomes of Implant Prostheses in Fibula Free Flaps', World Journal of Dentistry, 8(3), pp. 171-176.

Jain, A. R. (2017b) 'Prevalence of Partial Edentulousness and Treatment needs in Rural Population of South India', World Journal of Dentistry, 8(3), pp. 213-217. Kurtulmus-Yilmaz, S. et al. (2014) 'Digital evaluation of the accuracy of impression techniques and materials in angulated implants', Journal of dentistry, 42(12), pp. 1551-1559.

Lee, H. et al. (2008) 'The accuracy of implant impressions: A systematic review', The Journal of Prosthetic Dentistry, pp. 285-291. doi: 10.1016/s00223913(08)60208-5.

Lee, J.-H. et al. (2005) 'Effect of implant size and shape on implant success rates: A literature review', The Journal of Prosthetic Dentistry, pp. 377-381. doi: 10.1016/j.prosdent.2005.04.018.

Lin, C.-C. et al. (2020) 'Fully Digital Workflow for Planning Static Guided Implant Surgery: A Prospective Accuracy Study', Journal of Clinical Medicine, p. 980. doi: $10.3390 / j \mathrm{jm} 9040980$.

Lindh, T. et al. (1998) 'A meta-analysis of implants in partial edentulism', Clinical oral implants research, 9(2), pp. 80-90.

Misch, C. E. (1999) 'Contemporary Implant Dentistry', Implant Dentistry, p. 90. doi: 10.1097/00008505199901000-00012.

Misch, C. E. (2001) 'The importance of dental implants', General dentistry, 49(1), pp. 38-45.

Mojon, P. et al. (1990) 'Polymerization shrinkage of index and pattern acrylic resins', The Journal of Prosthetic Dentistry, pp. 684-688. doi: 10.1016/00223913(90)90296-o.

Ozan, 0. and Hamis, 0. (2019) 'Accuracy of different definitive impression techniques with the all-on-4 protocol', The Journal of prosthetic dentistry, 121(6), pp. 941-948.

Pyo, S.-W. et al. (2019) 'Methods Used to Assess the 3D Accuracy of Dental Implant Positions in ComputerGuided Implant Placement: A Review', Journal of clinical medicine research, 8(1). doi: 10.3390/jcm8010054.

Ranganathan, H., Ganapathy, D. M. and Jain, A. R. (2017) 'Cervical and Incisal Marginal Discrepancy in Ceramic Laminate Veneering Materials: A SEM Analysis', Contemporary clinical dentistry, 8(2), pp. 272-278.

cen, N., Nazmiye, 囚. E. N. and Us, Y. Ö. (2019) 'Abutment Selection for Implant Supported Fixed Prosthodontic Restorations', Turkiye Klinikleri Journal of Dental Sciences, pp. 104-112. doi: 10.5336/dentalsci.201757252.

Sorrentino, R. et al. (2010) 'Effect of implant angulation, connection length, and impression material on the dimensional accuracy of implant impressions: an in vitro comparative study', Clinical implant dentistry and related research, 12 Suppl 1, pp. e63-76.

Varghese, S. S., Ramesh, A. and Veeraiyan, D. N. (2019) 'Blended Module-Based Teaching in Biostatistics and Research Methodology: A Retrospective Study with Postgraduate Dental Students', Journal of dental education, 83(4), pp. 445-450.

Vercruyssen, M. et al. (2015) 'Computer-supported implant planning and guided surgery: a narrative review', Clinical oral implants research, 26 Suppl 11, pp. 69-76.

Vigolo, P., Majzoub, Z. and Cordioli, G. (2003) 'Evaluation of the accuracy of three techniques used for multiple implant abutment impressions', The Journal of Prosthetic Dentistry, pp. 186-192. doi: 10.1067/ mpr.2003.15.

Wee, A. G. (2000) 'Comparison of impression materials for direct multi-implant impressions', The Journal of Prosthetic Dentistry, pp. 323-331. doi: 10.1016/s00223913(00)70136-3. 